\title{
Haploinsufficiency of Bcl11b suppresses the progression of ATM-deficient T cell lymphomas
}

\author{
Kerice A. Pinkney ${ }^{3,5+}$, Wenxia Jiang ${ }^{1,2+}$, Brian J. Lee ${ }^{1}$, Denis G. Loredan ${ }^{1}$, Chen Li', Govind Bhagat ${ }^{2,4}$ \\ and Shan Zha ${ }^{1,2,3,4^{*}}$
}

\begin{abstract}
Bcl11 b is a transcription factor important for T cell development and also a tumor-suppressor gene that is hemizygously inactivated in $~ 10 \%$ human T cell acute lymphoblastic leukemia (T-ALL) and several murine T-ALL models, including $\mathrm{ATM}^{-/-}$thymic lymphomas. Here we report that heterozygous loss of Bcl11b $\left(\mathrm{Bcl} 11 \mathrm{~b}^{+/-}\right)$ unexpectedly reduced lethal thymic lymphoma in $\mathrm{ATM}^{-/-}$mice by suppressing lymphoma progression, but not initiation. The suppression was associated with a T cell-mediated immune response in $\mathrm{ATM}^{-/-} \mathrm{Bcl}^{11} 1 \mathrm{~b}^{+/-}$mice, revealing a haploid insufficient function of Bcl11b in immune modulation against lymphoma and offering an explanation for the complex relationship between Bcl11b status with T-ALL prognosis.
\end{abstract}

\section{Correspondence/findings}

Bcl11b is a transcription factor that is "monoallelically" inactivated in $\sim 10 \%$ of human $\mathrm{T}$ cell acute lymphoblastic leukemia (T-ALL) [1-3] and several murine T-ALL models, including $\mathrm{ATM}^{-/-}$thymic lymphomas [4-6]. Both human and murine T-ALLs retain at least one intact copy of Bcl11b, indicating that Bcl11b is a bona fide haploinsufficient tumor-suppressor gene. Complete loss of the Bcl11b gene abrogates $\mathrm{T}$ cell development and gain of NK cell phenotype, revealing a critical role of Bcl11b in $\mathrm{T}$ cell lineage commitment [7-10]. Conditional inactivation of both copies of Bcl11b in double-positive (DP) T cells leads to overproduction of innate $\mathrm{CD}^{+}$single-positive (SP) $\mathrm{T}$ cells [11] and compromises T-regulatory cell function [12]. Yet, hemizygous loss of Bcl11b has no measurable impact on $\mathrm{T}$ cell function [7-10] and the mechanism by which it promotes T-ALL remains elusive.

To address this, we characterized $\mathrm{Bcl}_{1} 1 \mathrm{~b}^{+/-} \mathrm{ATM}^{-/-}$mice $[6,13]$. ATM kinase is a master regulator of the DNA damage responses [14]. $\mathrm{ATM}^{-/-}$mice routinely succumb to immature $\mathrm{T}$ cell lymphomas sharing molecular features with human T-ALL. Of the $\mathrm{ATM}^{-/-}$thymic lymphomas,

\footnotetext{
* Correspondence: sz2296@columbia.edu

${ }^{\dagger}$ Equal contributors

'Institute for Cancer Genetics, Columbia University, 1130 St Nicholas Ave, RM 503B, New York, NY 10032, USA

${ }^{2}$ Herbert Irving Comprehensive Cancer Research Center, Columbia University, 1130 St Nicholas Ave, New York, NY 10032, USA

Full list of author information is available at the end of the article
}

$80 \%$ hemizygously deleted Bcl11b as a result of non-reciprocal $t(12 ; 14)$ translocation $[6,15]$. Conditional inactivation of Bcl11b in T cells via LckCre eliminates recurrent $t(12 ; 14)$ translocations from $\mathrm{ATM}^{-/-}$thymic lymphomas, suggesting $\mathrm{Bcl} 11 \mathrm{~b}$ as the target of the large chromosome 12 deletion [16]. $\mathrm{ATM}^{-1-} \mathrm{Bcll1b}^{+/-}$mice were born at expected frequency (Additional file 1: Figure S1A). Thymocyte development and peripheral $\mathrm{T}$ and $\mathrm{B}$ cell repertoire in young (4 week) $\mathrm{ATM}^{-/-} \mathrm{Bcl}_{11} \mathrm{~b}^{+/-}$mice were indistinguishable from that of $\mathrm{ATM}^{-/-}$mice, displaying reduced surface $\mathrm{TCR} \beta / \mathrm{CD} 3 \varepsilon$ expression in DP cells and a partial blockade at the DP to SP transition characteristic for ATMdeficiency $[6,17]$ (Additional file 1: Figure S1B).

While we initially expected Bcl11b-deficiency to accelerate ATM-deficient thymic lymphomas based on its frequent inactivation in T-ALLs, hemizygousdeletion of Bcl11b prevented lethal thymic lymphoma in $\sim 50 \% \mathrm{ATM}^{-/-}$mice and only $2 / 11 \mathrm{ATM}^{-/-} \mathrm{Bcl}_{11} \mathrm{~b}^{+/-}$ mice developed overt thymic lymphomas (Fig. 1a). The median survival of $\mathrm{ATM}^{-/-} \mathrm{Bcl}_{11 \mathrm{~b}} \mathrm{~b}^{+-}$mice was significantly longer than that of $\mathrm{ATM}^{-/-}$controls (167 vs. 106 days, $p<0.01$ ) (Fig. 1a). Analyses of 3- and 10-monthold $\mathrm{ATM}^{-/-} \mathrm{Bcl1} 1 \mathrm{~b}^{+/-}$mice revealed clonal expansion of immature (surfaceTCR $\beta^{\text {low }}$ ) thymocytes in 3-month, but not 10-month-old $\mathrm{ATM}^{-/-} \mathrm{Bcl}_{11 \mathrm{~b}^{+-}}$mice (Fig. 1b, c). T cell lymphomas from 3-month-old $\mathrm{ATM}^{-/-} \mathrm{Bcl}_{11} \mathrm{~b}^{+/-}$mice retained both WT and null alleles of Bcl11b, consistent with the lack-of-LOH in T-ALL (Fig. 1d). Despite the clonal 
A

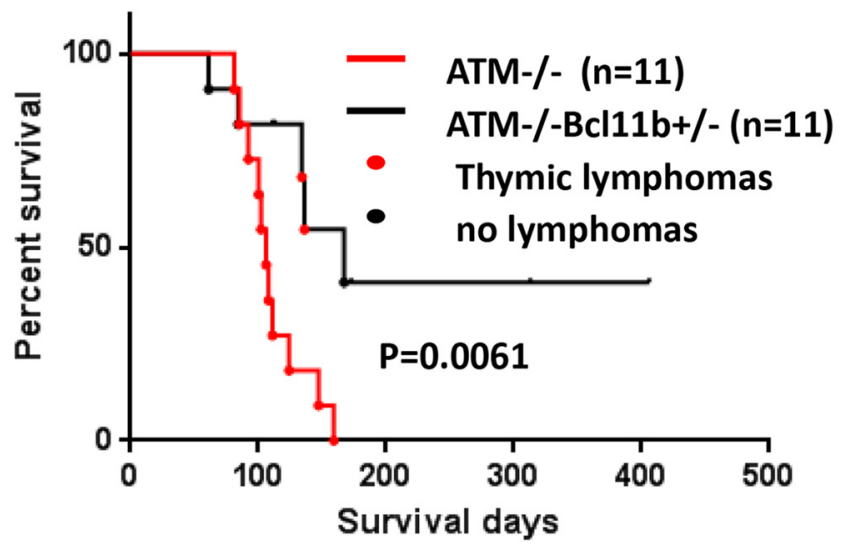

B

WT
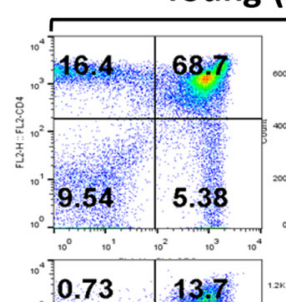

ATM-/$\mathrm{Bcl} 11 \mathrm{~b}+/-$

6203
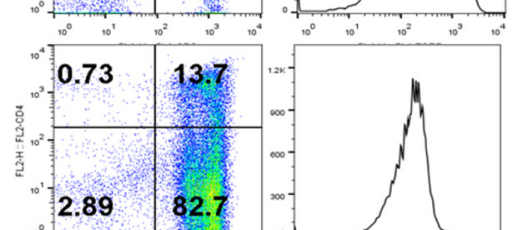

ATM-/$\mathrm{Bcl11b+/-}$

6319

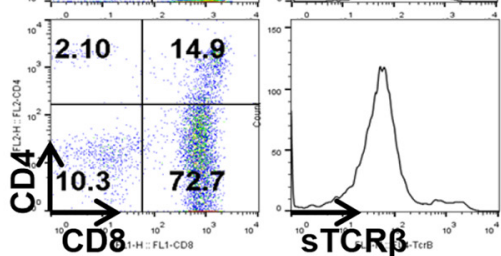

C

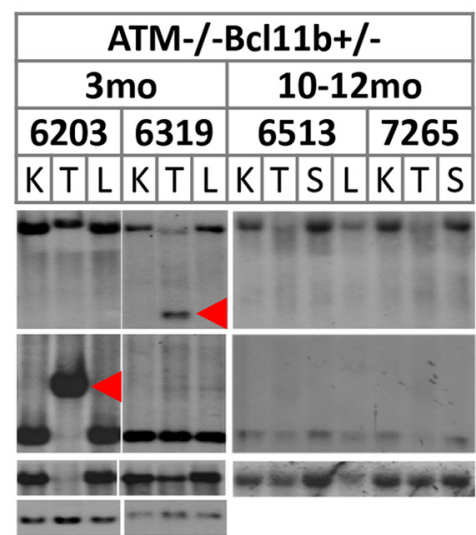

Old (10-12 mo)

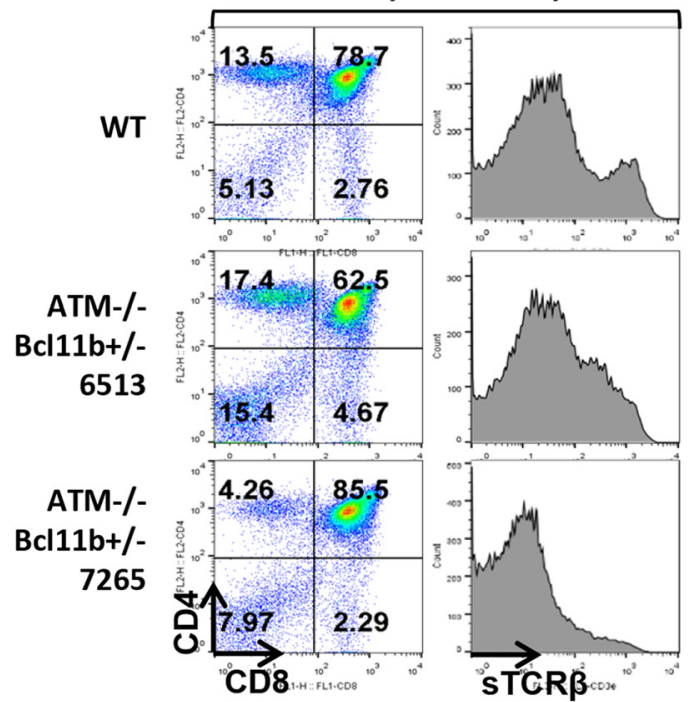

D

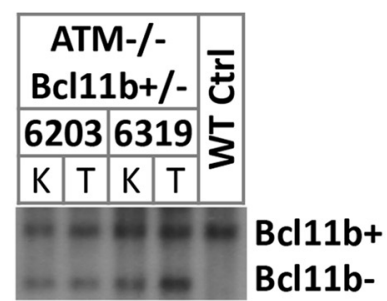

\section{J $\mathbf{B} 2.7$}

\section{$C \delta$} Amp

Fig. 1 Heterozygous loss of Bcl11b suppresses the progression, but not the initiation of ATM-deficient thymic lymphomas. a Thymic lymphomafree survival of $\mathrm{ATM}^{-/-}$and $\mathrm{ATM}^{-/-} \mathrm{BCl} 11 \mathrm{~b}^{+/-}$mice. Median survival of $\mathrm{ATM}^{-/-}$and $\mathrm{ATM}^{-/-} \mathrm{Bcl}^{1} 1 \mathrm{bb}^{+/-}$cohorts was 106 and 169 days, respectively. $p$ value for log-ranking test is 0.0061 . b Representative flow cytometry analyses of the thymus from control and $\mathrm{ATM}^{-/-} \mathrm{Bcl}_{11 \mathrm{~b}^{+/-}}$mice at 3 or 10 months of age. c Southern blot analyses of EcoRI digested genomic DNA from kidney (K), thymus (T), enlarged submandibular lymph nodes

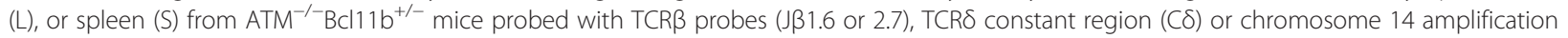
region (Amp) [6]. d Southern blot analyses of Bcl11b locus on Kpnl digested genomic DNA with Bcl11b probe [13] 


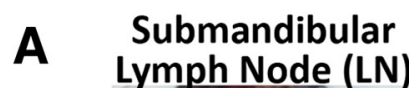

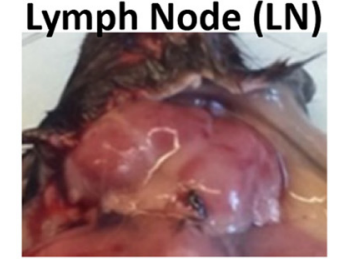

B
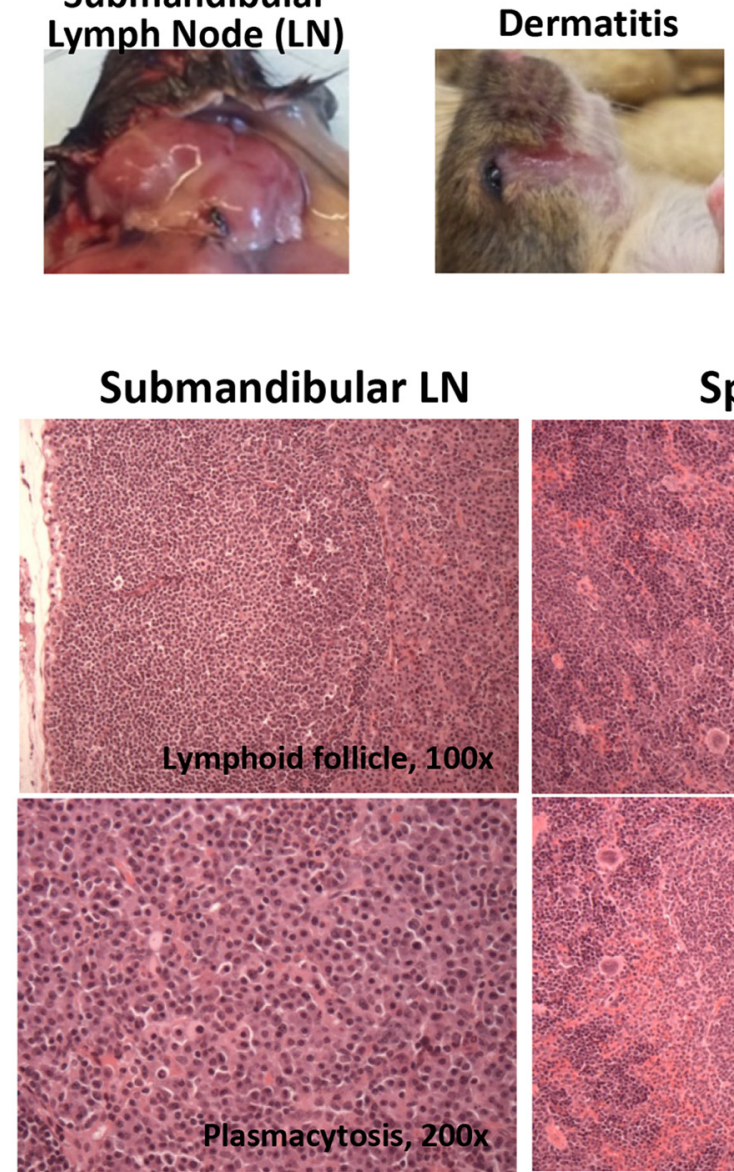

Splenomegaly
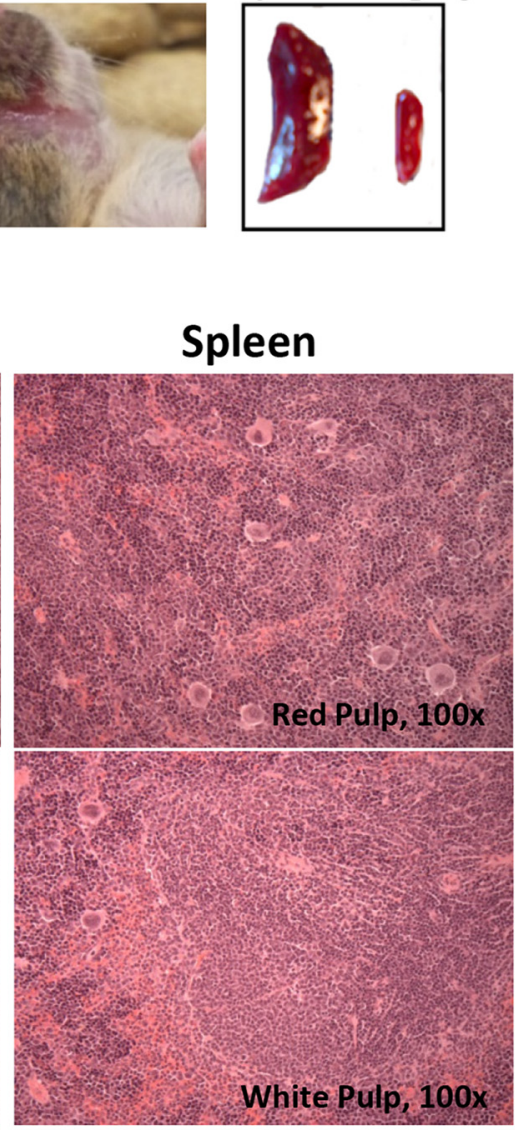

C

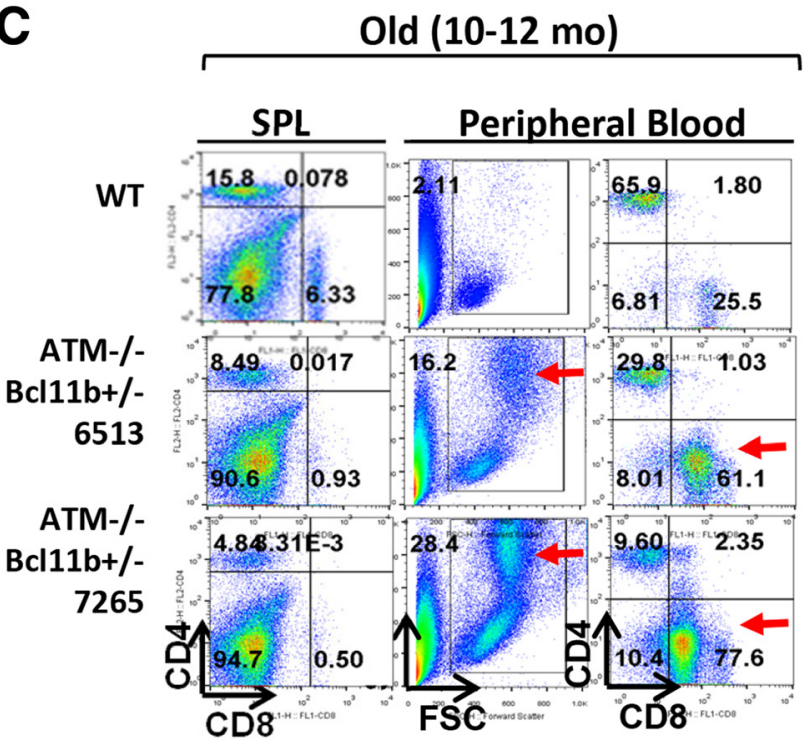

Fig. 2 Heterozygous loss of Bcl11b induces an inflammatory/immune response in $\mathrm{ATM}^{-/-}$mice. a Representative pictures of enlarged submandibular lymph nodes, dermatitis, and splenomegaly in $\mathrm{ATM}^{-/-} \mathrm{Bcl1} 1 \mathrm{~b}^{+/-}$mice. $\mathbf{b}$ Histopathologic analysis of the submandibular lymph nodes and spleen in $\mathrm{ATM}^{-1-} \mathrm{Bcl} 11 \mathrm{~b}^{+/-}$mice. c Flow cytometry analysis shows significant enrichment of CD8 ${ }^{+} \mathrm{SP}$ T cells in the peripheral blood,

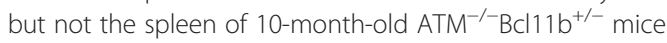


expansion in 3-month-old $\mathrm{ATM}^{-/} \mathrm{Bcl}_{11} \mathrm{~b}^{+/-}$mice, most thymic lymphomas failed to progress to lethal disease (Additional file 1: Figure S1C), suggesting that heterozygous Bcl11b-deficiency suppresses the progression, but not the initiation of $\mathrm{ATM}^{-/-}$thymic lymphomas.

Notably, almost all $\mathrm{ATM}^{-/-} \mathrm{Bcl}_{11} \mathrm{~b}^{+/-}$mice developed variable degrees of splenomegaly, excessive submandibular lymph node ( $\mathrm{LN})$ enlargement that manifested to fatal airway obstruction (non-lymphoma-related death), and dermal inflammation commencing at 2-3 months of age (Fig. 2a). In contrast to normal lymphocyte profiles in 3month-old $\mathrm{ATM}^{+/+(+/)} \mathrm{Bcl} 11 \mathrm{~b}^{+/-}$mice (Additional file 1: Figure S2A and S2B), histologic analyses consistently revealed a lymphocyte-mediated inflammatory/immune disorder in $\mathrm{ATM}^{-/-} \mathrm{Bcl}_{11} \mathrm{~b}^{+/-}$mice characterized by marked plasmacytosis with reactive germinal centers $\left(\mathrm{B}_{220} \mathrm{IgM}^{+} \mathrm{Bcl6}^{+} \mathrm{CD} 138^{-} \mathrm{B}\right.$ cells) in submandibular LN, reactive follicular hyperplasia of the white pulp and increased extramedullary hematopoiesis in the red pulp in the spleen (Fig. 2b and Additional file 1: Figure S2C), and acute and chronic dermal inflammation in the skin. While a cell-autonomous function of Bcl11b deletion on epidermal integrity cannot be ruled out [13], the splenic and LN changes noted raised the possibility of an autoimmune disorder, which could have contributed to the lack of tumor progression in $\mathrm{ATM}^{-/-} \mathrm{Bcll1b}^{+/-}$mice. Correspondingly, 10-month tumor-free $\mathrm{ATM}^{-/} \mathrm{Bcl}^{1} 1 \mathrm{~b}^{+/-}$mice accumulated activated $\mathrm{CD} 8^{+} \mathrm{T}$ cell in $\mathrm{PB}$ (Fig. 2c).

Our data suggest that in an ATM-deficient background, heterozygous Bcl11b deficiency tilts immune homeostasis and limits the expansion, but not the initiation of ATM-deficient thymic lymphomas. Notably, homozygous Bcl11b deletion suppressed melanoma in murine models [18]. Given the role of Bcl11b in T cell lineage commitment, $\mathrm{CD}^{+} \mathrm{T}$ cell development, and $\mathrm{T}$ reg function, our data suggest that heterozygous Bcl11b deficiency can modulate anti-tumor immune response despite the lack of measurable $\mathrm{T}$ cell development defects in Bcl11b ${ }^{+/-}$mice [7-10]. This role of Bcl11b in immune modulation and tumor suppression might explain the discrepancies between Bcl11b status (mutation, deletion, and downregulation) and T-ALL prognosis in different studies $[1-3,19]$. It also suggests that Bcl11b is likely lost later during T-ALL development, as early deletion likely causes autoimmune dysfunction, analogous to TNFAIP3 (A20) in DLBCL [20].

\section{Additional file}

Additional file 1: Figure S1. Characterization of T cell development in $\mathrm{ATM}^{-/-} \mathrm{BCl} 11 \mathrm{~b}^{+/-}$mice. (A) Actual and expected offspring from breeding between Bcl1 1 b ${ }^{+/-}$ATM $^{+-}$and ATM $^{+/-}$mice. The $p$ value calculated based on chi-squared test is 0.89 . (B) Representative flow cytometric analysis of pre-malignant thymocytes from $\mathrm{WT}, \mathrm{ATM}^{-/-}$and $\mathrm{ATM}^{-/-} \mathrm{BCl} 11 \mathrm{~b}^{+/-}$ mice (4-6 weeks). Figure S2. Analyses of autoimmunity in $\mathrm{ATM}^{-/-} \mathrm{BCl} 11 \mathrm{~b}^{+/}$ mice. (A) Flow cytometric analysis of the spleen, bone marrow, and lymph nodes from 3-month and 10-month-old $\mathrm{ATM}^{-/-} \mathrm{Bcl} 11 \mathrm{~b}^{+/-}$mice. Notably, the frequency of the CD11 b myeloid cells increases in the spleen of $\mathrm{ATM}^{-/-}$ $\mathrm{BCl} 11 \mathrm{~b}^{+/-}$mice, consistent with increased extramedullary hematopoiesis in the red pulp seen in Fig. 2b. (B) Flow cytometric analyses of the thymus and spleen (SPL) from 3-month-old littermate $\mathrm{ATM}^{+/+} \mathrm{BCl}_{1} 1 \mathrm{~b}^{+/+}(\mathrm{WT}), \mathrm{BCl} 11 \mathrm{~b}^{+/-}$, $\mathrm{ATM}^{+/-} \mathrm{BCl} 11 \mathrm{~b}^{+/-}$mice. Double negative (DN) staining was performed on gated CD8-CD4-CD19-TCRy/ $\delta^{-}$thymocytes. Homozygous deletion of Bcl1 1b dramatically increased the number of phenotypical NK cells $[8,9]$. The percentage of $\mathrm{NK} 1.1^{+}$or $\mathrm{CD}^{+}$cells does not significantly increase in the thymus and spleen of 3-month-old $\mathrm{BCl} 11 \mathrm{~b}^{+/-}$mice. (C) Immunohistochemical staining with germinal center marker Bcl6 and plasma cell marker CD138 of the enlarged submandibular lymph nodes. (PDF 2082 kb)

\section{Abbreviations}

ALL: acute lymphoblastic leukemia; ATM: ataxia telangiectasia mutated; BM: bone marrow; DN: double negative; DP: double positive; LN: lymph node; PB: peripheral blood; SP: single positive; SPL: spleen.

\section{Authors' contributions}

WJ, KP, and SZ designed the experiments. KP, WJ, and SZ wrote the manuscript. GB performed the histopathologic analysis. $K P, W J, B J L, D G L, C L$, and SZ performed the experiments.

\section{Competing interests}

The authors declare that they have no competing interests.

\section{Acknowledgements}

We thank Drs. Mark Leid and Adolfo A. Ferrando for generously sharing the Bcl11b deficient mouse models and discussing the experimental results. We thank Ms. Hongyan Tang and Dr. David Dominguez-Sola in the laboratory of Dr. Riccardo Dalla-Favera for the help with the histopathology analyses. We also wish to apologize to colleagues, whose work could not be cited due to space limitations. This work is in part supported by NIH/NCI R01CA158073, $\mathrm{NIH} / \mathrm{NCI}$ R01CA184187, NIH/NIAID R21Al103826, and American Cancer Society Research Scholar Grant (RSG-13-038-01 DMC) to SZ and NIH/NCI 1P01CA174653-01 to both SZ and GB. SZ is the recipient of Leukemia Lymphoma Society Scholar Award. KP is a St Baldrick's Fellow for Pediatric Cancer and WJ was in part supported by NIH/NCI T32-CA09503. All animal experiments were conducted within the guidelines of Columbia University Institution Animal Use and Care Committee (protocol number AAAF7653 and AAAJ3651).

\section{Author details}

${ }^{1}$ Institute for Cancer Genetics, Columbia University, 1130 St Nicholas Ave, RM 503B, New York, NY 10032, USA. ${ }^{2}$ Herbert Irving Comprehensive Cancer Research Center, Columbia University, 1130 St Nicholas Ave, New York, NY 10032, USA. ${ }^{3}$ Department of Pediatrics, Division of Hematology, Oncology and Stem Cell Transplantation, Columbia University, 1130 St Nicholas Ave, New York, NY 10032, USA. Department of Pathology and Cell Biology, College for Physicians and Surgeons, Columbia University, 1130 St Nicholas Ave, New York, NY 10032, USA. ${ }^{5}$ Current address: Joe DiMaggio's Children's Hospital, 1150 North 35th Avenue, Suite 100, Hollywood, FL 33021, USA.

Received: 23 April 2015 Accepted: 17 July 2015

Published online: 30 July 2015

\section{References}

1. De Keersmaecker K, Real PJ, Gatta GD, Palomero T, Sulis ML, Tosello V, et al. The TLX1 oncogene drives aneuploidy in T cell transformation. Nat Med. 2010;16(11):1321-7.

2. Gutierrez A, Kentsis A, Sanda T, Holmfeldt L, Chen SC, Zhang J, et al. The BCL11B tumor suppressor is mutated across the major molecular subtypes of T-cell acute lymphoblastic leukemia. Blood. 2011;118(15):4169-73.

3. Bartram I, Gokbuget N, Schlee C, Heesch S, Fransecky L, Schwartz S, et al. Low expression of T-cell transcription factor BCL11b predicts inferior survival in adult standard risk T-cell acute lymphoblastic leukemia patients. Journal of Hematology \& Oncology. 2014;7:51. 
4. Wakabayashi Y, Inoue J, Takahashi Y, Matsuki A, Kosugi-Okano H, Shinbo T, et al. Homozygous deletions and point mutations of the Rit1/Bcl11b gene in gamma-ray induced mouse thymic lymphomas. Biochem Biophys Res Commun. 2003;301(2):598-603.

5. Kamimura K, Ohi H, Kubota T, Okazuka K, Yoshikai Y, Wakabayashi Y, et al. Haploinsufficiency of Bcl11b for suppression of lymphomagenesis and thymocyte development. Biochem Biophys Res Commun. 2007;355(2):538-42.

6. Zha S, Bassing CH, Sanda T, Brush JW, Patel H, Goff PH, et al. ATM-deficient thymic lymphoma is associated with aberrant tcrd rearrangement and gene amplification. Journal of Experimental Medicine. 2010;207(7):1369-80.

7. Ikawa T, Hirose S, Masuda K, Kakugawa K, Satoh R, Shibano-Satoh A, et al. An essential developmental checkpoint for production of the $T$ cell lineage. Science. 2010;329(5987):93-6.

8. Li L, Leid M, Rothenberg EV. An early T cell lineage commitment checkpoint dependent on the transcription factor Bcl11b. Science. 2010;329(5987):89-93.

9. Li P, Burke S, Wang J, Chen X, Ortiz M, Lee SC, et al. Reprogramming of T cells to natural killer-like cells upon Bcl11b deletion. Science. 2010;329(5987):85-9.

10. Wakabayashi Y, Watanabe H, Inoue J, Takeda N, Sakata J, Mishima Y, et al. $\mathrm{BCl} 11 \mathrm{~b}$ is required for differentiation and survival of alphabeta $\mathrm{T}$ lymphocytes. Nat Immunol. 2003;4(6):533-9.

11. Hirose S, Touma M, Go R, Katsuragi Y, Sakuraba Y, Gondo Y, et al. Bcl11b prevents the intrathymic development of innate CD8 T cells in a cell intrinsic manner. International Immunology. 2014;27(4):205-15.

12. Vanvalkenburgh J, Albu DI, Bapanpally C, Casanova S, Califano D, Jones DM, et al. Critical role of Bcl11b in suppressor function of T regulatory cells and prevention of inflammatory bowel disease. J Exp Med. 2011;208(10):2069-81.

13. Golonzhka O, Liang X, Messaddeq N, Bornert JM, Campbell AL, Metzger D, et al. Dual role of COUP-TF-interacting protein 2 in epidermal homeostasis and permeability barrier formation. J Invest Dermatol. 2009;129(6):1459-70.

14. Lavin MF. Ataxia-telangiectasia: from a rare disorder to a paradigm for cell signalling and cancer. Nat Rev Mol Cell Biol. 2008;9(10):759-69.

15. Jiang W, Lee BJ, Li C, Dubois RL, Gostissa M, Alt FW, et al. Aberrant TCR rearrangement underlies the T-cell lymphocytopenia and $t(12 ; 14)$ translocation associated with ATM deficiency. Blood. 2015;125(17):2665-8.

16. Ehrlich LA, Yang-lott $K$, Bassing $\mathrm{CH}$. Tcrdelta translocations that delete the Bcl11b haploinsufficient tumor suppressor gene promote atm-deficient T cell acute lymphoblastic leukemia. Cell Cycle. 2014;13(19):3076-82.

17. Borghesani PR, Alt FW, Bottaro A, Davidson L, Aksoy S, Rathbun GA, et al. Abnormal development of Purkinje cells and lymphocytes in Atm mutant mice. Proc Natl Acad Sci USA. 2000;97(7):3336-41.

18. Uddin MN, Zhang Y, Harton JA, MacNamara KC, Avram D. TNF-alpha-dependent hematopoiesis following Bcl11b deletion in T cells restricts metastatic melanoma. J Immunol. 2014;192(4):1946-53.

19. Van Vlierberghe P, Ambesi-Impiombato A, De Keersmaecker K, Hadler M, Paietta E, Tallman MS, et al. Prognostic relevance of integrated genetic profiling in adult T-cell acute lymphoblastic leukemia. Blood. 2013;122(1):74-82.

20. Ma A, Malynn BA. A20: linking a complex regulator of ubiquitylation to immunity and human disease. Nat Rev Immunol. 2012;12(11):774-85.

\section{Submit your next manuscript to BioMed Central and take full advantage of:}

- Convenient online submission

- Thorough peer review

- No space constraints or color figure charges

- Immediate publication on acceptance

- Inclusion in PubMed, CAS, Scopus and Google Scholar

- Research which is freely available for redistribution

Submit your manuscript at www.biomedcentral.com/submit 